\title{
As licenciaturas e as novas políticas educacionais para a formação docente
}

\author{
Júlio Emílio Diniz Pereira
}

\begin{abstract}
RESUMO: Neste artigo são apresentadas reflexões e análises a respeito das recentes políticas educacionais para a formação docente no Brasil. O foco são as diferentes questões que envolvem os cursos de licenciatura no país, principalmente, a partir da aprovação da Lei de Diretrizes e Bases da Educação Nacional (lei n ${ }^{0}$ 9.394/96). Mais especificamente, são discutidos os modelos de formação docente - subjacentes às formulações atuais e a serem implementadas -, as demandas para a formação profissional resultantes das mudanças na educação básica brasileira, o locus da preparação de professores e o processo de construção das diretrizes curriculares para as licenciaturas.
\end{abstract}

Palavras-chave: Política educacional, formação de professores, licenciaturas

\section{Introdução}

Após cerca de 15 anos de silêncio na política educacional brasileira para a formação docente, volta-se a viver um intenso debate sobre a legislação que regulamentará a formação dos profissionais da educação no país. Apesar da carência de novas leis para a preparação dos educadores nesse período, a formação de professores tornou-se tema recorrente nas discussões acadêmicas dos últimos 30 anos. Com a cri-

\footnotetext{
*Professor na Universidade Federal de Minas Gerais (UFMG). Email: jpereira@dedalus.lcc.ufmg.br
} 
ação das faculdades ou centros de educação nas universidades brasileiras, em 1968, a formação docente constitui-se em objeto permanente de estudos nesses espaços. É evidente, também, o crescimento da investigação sobre a profissão docente nas universidades e instituições de pesquisa no Brasil, principalmente a partir da década de 1990, o que tem possibilitado um debate fundamentado em análises empíricas e teóricas e, por conseguinte, uma discussão mais qualificada sobre o tema. Todavia, as licenciaturas, cursos que habilitam para o exercício dessa profissão no país, permanecem, desde sua origem na década de 1930, sem alterações significativas em seu modelo.

Como se sabe, a Lei de Diretrizes e Bases da Educação Nacional (LDB - lei no 9.394/96) foi, sem dúvida alguma, responsável por uma nova onda de debates sobre a formação docente no Brasil. Antes mesmo da aprovação dessa lei, o seu longo trânsito no Congresso Nacional suscitou discussões a respeito do novo modelo educacional para o Brasil e, mais especificamente, sobre os novos parâmetros para a formação de professores. Como conseqüência, depois de acirrada oposição de interesses, prevaleceram, no texto da LBD, os elementos centrais do substitutivo Darcy Ribeiro, afinado com a política educacional do governo Fernando Henrique Cardoso, porém, com algumas modificações conseguidas em virtude do embate parlamentar.

Sendo assim, a versão final dessa lei foi construída mediante a participação de diferentes sujeitos e atores sociais. Isso fez com que ela assumisse um caráter "polifônico" - segundo expressão usada por Carlos Jamil Cury -, em que distintas vozes podem ser ouvidas a partir da leitura de seu texto. Na parte mais específica sobre formação docente (Título VI - Dos profissionais da educação), por exemplo, essa característica é bastante evidente. Nela convivem termos e expressões que contêm idéias inconciliáveis, como, de um lado, "programas de formação pedagógica para portadores de diplomas de educação superior", "institutos superiores de educação", "curso normal superior", e, de outro, "profissionais da educação" e "base comum nacional".

Para melhor compreender as atuais discussões a respeito da formação de professores e as recentes políticas regulamentadoras dessa atividade, é importante lembrar o contexto mais amplo em que a LDB foi aprovada. Na época, particularmente na América Latina, respirava-se uma atmosfera hegemônica de políticas neoliberais, de interesse do capital financeiro, impostas por intermédio de agências como Banco Mundial e Fundo Monetário Internacional (FMI), que procuravam promover a 
reforma do Estado, minimizando o seu papel, e favorecer o predomínio das regras do mercado em todos os setores da sociedade, incluindo as atividades educacionais.

É importante também não esquecer, quando se discute a questão da formação docente, as atuais condições da educação brasileira. Isso porque são vários os fatores externos ao processo pedagógico que vêm prejudicando a formação inicial e continuada dos professores no país, destacando-se o aviltamento salarial e a precariedade do trabalho escolar. Sabe-se que o desestímulo dos jovens à escolha do magistério como profissão futura e a desmotivação dos professores em exercício para buscar aprimoramento profissional são conseqüência, sobretudo, das más condições de trabalho, dos salários pouco atraentes, da jornada de trabalho excessiva e da inexistência de planos de carreira.

Finalmente, o conjunto de leis que, há pouco tempo, vem sendo formulado para regulamentar a formação docente no Brasil parece interessado em romper com o atual modelo de preparação dos profissionais da educação. Por outro lado, a urgência em qualificar um grande número de educadores para uma população escolar crescente sem o correspondente investimento financeiro por parte do governo poderá levar à repetição de erros cometidos em um passado próximo e, conseqüentemente, corre-se o risco de reviver cenários de improvisação, aligeiramento e desregulamentação na formação de professores no país.

\section{Os atuais modelos de formação docente no Brasil ${ }^{2}$}

No Brasil, como se sabe, as licenciaturas foram criadas nas antigas faculdades de filosofia, nos anos 30 , principalmente como conseqüência da preocupação com a regulamentação do preparo de docentes para a escola secundária. Elas constituíram-se segundo a fórmula "3 +1 ", em que as disciplinas de natureza pedagógica, cuja duração prevista era de um ano, justapunham-se às disciplinas de conteúdo, com duração de três anos.

Essa maneira de conceber a formação docente revela-se consoante com o que é denominado, na literatura educacional, de modelo da racionalidade técnica. Nesse modelo, o professor é visto como um técnico, um especialista que aplica com rigor, na sua prática cotidiana, as 
regras que derivam do conhecimento científico e do conhecimento pedagógico. Portanto, para formar esse profissional, é necessário um conjunto de disciplinas científicas e um outro de disciplinas pedagógicas, que vão fornecer as bases para sua ação. No estágio supervisionado, o futuro professor aplica tais conhecimentos e habilidades científicas e pedagógicas às situações práticas de aula.

Esse modelo de formação docente pode ser descrito, também, segundo a conhecida analogia com o "curso de preparação de nadadores" criada por Jacques Busquet, em 1974:

Imagine uma escola de natação que se dedica um ano a ensinar anatomia e fisiologia da natação, psicologia do nadador, química da água e formação dos oceanos, custos unitários das piscinas por usuário, sociologia da natação (natação e classes sociais), antropologia da natação (o homem e a água) e, ainda, a história mundial da natação, dos egípcios aos nossos dias. Tudo isso, evidentemente, à base de cursos enciclopédicos, muitos livros, além de giz e quadro-negro, porém sem água. Em uma segunda etapa, os alunos-nadadores seriam levados a observar, durante outros vários meses, nadadores experientes; depois dessa sólida preparação, seriam lançados ao mar, em águas bem profundas, em um dia de temporal.

Parece consenso que os currículos de formação de professores, baseados no modelo da racionalidade técnica, mostram-se inadequados à realidade da prática profissional docente. As principais críticas atribuídas a esse modelo são a separação entre teoria e prática na preparação profissional, a prioridade dada à formação teórica em detrimento da formação prática e a concepção da prática como mero espaço de aplicação de conhecimentos teóricos, sem um estatuto epistemológico próprio. Um outro equívoco desse modelo consiste em acreditar que para ser bom professor basta o domínio da área do conhecimento específico que se vai ensinar.

Nas universidades brasileiras, esse modelo ainda não foi totalmente superado, já que disciplinas de conteúdo específico, de responsabilidade dos institutos básicos, continuam precedendo as disciplinas de conteúdo pedagógico e articulando-se pouco com elas, as quais, geralmente, ficam a cargo apenas das faculdades ou centros de educação. Além disso, o contato com a realidade escolar continua acontecendo, com 
mais freqüência, apenas nos momentos finais dos cursos e de maneira pouco integrada com a formação teórica prévia (Pereira 1998).

Nas demais instituições de Ensino Superior, em especial nas particulares e nas faculdades isoladas, é a racionalidade técnica que, igualmente, predomina nos programas de preparação de professores, apesar de essas instituições oferecerem, na maioria das vezes, apenas a licenciatura e, conseqüentemente, de a formação docente ser realizada desde o primeiro ano. Trata-se de uma licenciatura inspirada em um curso de bacharelado, em que o ensino do conteúdo específico prevalece sobre o pedagógico e a formação prática assume, por sua vez, um papel secundário.

Um modelo alternativo de formação de professores que vem conquistando um espaço cada vez maior na literatura especializada é o chamado modelo da racionalidade prática. Nesse modelo, o professor é considerado um profissional autônomo, que reflete, toma decisões e cria durante sua ação pedagógica, a qual é entendida como um fenômeno complexo, singular, instável e carregado de incertezas e conflitos de valores. De acordo com essa concepção, a prática não é apenas locus da aplicação de um conhecimento científico e pedagógico, mas espaço de criação e reflexão, em que novos conhecimentos são, constantemente, gerados e modificados.

Com base na crítica ao modelo da racionalidade técnica e orientadas pelo modelo da racionalidade prática, definem-se outras maneiras de representar a formação docente. As atuais políticas para preparo dos profissionais da educação, no país, parecem consoantes com esse outro modo de conceber tal formação. As propostas curriculares elaboradas desde então rompem com o modelo anterior, revelando um esquema em que a prática é entendida como eixo dessa preparação. Por essa via, o contato com a prática docente deve aparecer desde os primeiros momentos do curso de formação. Desse envolvimento com a realidade prática originam-se problemas e questões que devem ser levados para discussão nas disciplinas teóricas. Os blocos de formação não se apresentam mais separados e acoplados, como no modelo anterior, mas concomitantes e articulados.

Contudo, em virtude da necessidade urgente de se habilitar aqueles que, hoje, no país, estão em sala de aula, exercendo o magistério, corre-se o risco de as recentes políticas educacionais para formação docente favorecerem a improvisação no preparo dos profissionais da edu- 
cação. Em nome dessa urgência, a prática, que deve ocupar um espaço significativo nas grades curriculares dos cursos de licenciatura, pode ser compreendida erroneamente como formação em serviço. As horas trabaIhadas em sala de aula, sem, necessariamente, um planejamento e uma intencionalidade formativa, podem, assim, ser contabilizadas nos novos cursos de licenciatura pelos profissionais já em exercício na escola. Como conseqüência, diminui significativamente a carga horária dos cursos de formação inicial de professores, o que, obviamente, não é desejável e representa um imenso retrocesso em termos da preparação desses profissionais.

Do mesmo modo, o descuido com o embasamento teórico na formação de professores, indispensável no preparo desses profissionais, é extremamente prejudicial aos cursos de licenciatura. O rompimento com o modelo que prioriza a teoria em detrimento da prática não pode significar a adoção de esquemas que supervalorizem a prática e minimizem o papel da formação teórica. Assim como não basta o domínio de conteúdos específicos ou pedagógicos para alguém se tornar um bom professor, também não é suficiente estar em contato apenas com a prática para se garantir uma formação docente de qualidade. Sabe-se que a prática pedagógica não é isenta de conhecimentos teóricos e que estes, por sua vez, ganham novos significados quando diante da realidade escolar.

Além disso, ainda de acordo com a lógica da improvisação, profissionais de diferentes áreas são transformados em professores mediante uma complementação pedagógica de, no mínimo, 540 horas (LDB, art. 63, inciso I; Parecer CNE no 04/97). Desse total, 300 horas devem ser de prática de ensino (LDB, art. 65) e podem ser contabilizadas mediante capacitação em serviço (LDB, art. 61, inciso I). Ou seja, a legislação atual permite que profissionais egressos de outras áreas, em exercício no magistério, tornem-se professores valendo-se de um curso de formação docente de 240 horas! O que parece inconcebível em outros campos profissionais - como, por exemplo, direito, medicina e engenharia - é possível para o magistério, contrariando a própria denominação do Título VI da LDB, "Dos profissionais da educação". Diante dessa situação preocupante, perguntar-se-ia: A mesma urgência que justificou, na década de 1970, no Brasil, a criação dos cursos de licenciatura de curta duração está presente nas atuais proposições sobre formação docente? São os programas de formação pedagógica para portadores de diplomas de educação superior uma reedição atualizada dos desastrosos cursos de licenciatura curta? Esse esquema é uma infeliz legitimação do "bico" na profissão docente, 
uma vez que profissionais egressos de outras áreas, que não optaram, de início, pela carreira de magistério, provavelmente, só estão na profissão enquanto não conseguem algo melhor para fazer.

É inquestionável, portanto, que as atuais mudanças na estrutura jurídico-legal da educação brasileira tornam manifesta a necessidade da criação de um projeto pedagógico para a formação e a profissionalização de professores nas universidades e demais instituições de Ensino Superior brasileiras. Esse novo projeto pedagógico deve estar em consonância com as modificações pretendidas na educação básica. No entanto, uma leitura mais crítica do contexto permite afirmar que, nas recentes políticas educacionais, a formação de professores corre sérios riscos de improvisação, aligeiramento e desregulamentação.

\section{As mudanças na educação básica e a formação docente ${ }^{3}$}

De acordo com a LDB, a educação básica - agora compreendida como Educação Infantil, Ensino Fundamental e Ensino Médio (art. 21, inciso I) - deve perder seu caráter primordialmente propedêutico e refletir uma visão mais rica de aprendizagem e desenvolvimento dos educandos, segundo a qual cada idade tem importância em si, como fases de constituição de sujeitos, de vivências e socialização, de processos de construção de valores e identidades.

Essa visão está alicerçada na concepção de desenvolvimento e aprendizagem como processos, na idéia de que não se constróem conhecimentos significativos de forma cumulativa e no pressuposto de que os conhecimentos se produzem nas interações e vivências, em empreendimentos, na busca de respostas às perguntas que os educandos se fazem.

À medida que a reforma na educação básica se consolida, percebe-se que a tarefa de coordenar processos de desenvolvimento e aprendizagem é extremamente complexa e exige, já a partir da própria educação infantil, profissionais com formação superior. Esse, aliás, parece ter sido o entendimento dos legisladores quando escreveram o art. 62 da LDB, apesar de este continuar admitindo a formação em nível médio, na modalidade Normal, como a exigência mínima para exercício do magistério na educação infantil e nas quatro primeiras séries do Ensino Fundamental. 
Se, por um lado, é possível admitir-se que a concepção de educação básica se tornou mais avançada na legislação atual, por outro, quanto à obrigatoriedade desse nível da educação escolar, os progressos ainda são pequenos, pois o Ensino Fundamental é o único assegurado pelo Estado (LDB, art. 32). A Educação Infantil e o Ensino Médio, ainda que desejáveis para o conjunto da população, continuam sendo facultativos para uma grande maioria.

Segundo o art. 32 da LDB, a educação fundamental passa a ter duração mínima de oito anos e está voltada para a formação básica do cidadão. Esse nível de ensino escolar pode organizar-se de diferentes modos e, com isso, superar a clássica separação entre as quatro primeiras séries do Ensino Fundamental e seus quatro anos subseqüentes (de $5^{\mathrm{a}}$ a $8^{\mathrm{a}}$ série). A realidade, porém, apresenta enormes dificuldades para a articulação desses dois momentos, tanto pela estrutura diferenciada quanto pelo tipo de professor que atende a cada uma dessas etapas do Ensino Fundamental. Essa diferenciação, ainda carregada de características do antigo modelo do "primário" e do "ginásio", cria uma fragmentação muito significativa nas práticas escolares e nas vivências dos alunos.

Em relação aos profissionais, por exemplo, lembre-se que as professoras das séries iniciais se caracterizam por um perfil mais generalista e os professores do segundo segmento, por uma formação mais específica. Além disso, as professoras das primeiras séries têm habilidades que os professores de disciplinas não possuem, e vice-versa, o que cria descontinuidades não só no desenvolvimento das aprendizagens de conceitos essenciais, mas também no trato de processos mais globais.

Nesse sentido, para uma coerência com as mudanças pretendidas na educação brasileira e com as incumbências que são atribuídas aos docentes pela LDB (art. 13), torna-se necessário pensar a formação de um profissional que compreenda os processos humanos mais globais, seja ele um professor da educação infantil, dos primeiros ou dos últimos anos da escola básica. Um profissional capaz de refletir sobre as seguintes indagações: Como um indivíduo se desenvolve e aprende na infância, na adolescência e na fase adulta? Como a biologia, a sociologia, a psicologia, a antropologia, enfim, as diversas áreas do conhecimento vêm abordando essas fases de formação próprias da vida humana? Que interferência exercem as dimensões cognitivas, corporais, sociais, culturais e emocionais, bem como as múltiplas dimensões existenciais, na construção dos conhecimentos dos educandos? 
É preciso, então, imaginar a formação de um profissional que tenha vivências na escola básica, desde a infância, com a adolescência e jovens/adultos, e conheça seu cotidiano, suas construções, sua realidade. É interessante conceber um profissional que, ao assumir seu trabaIho com alunos adolescentes, por exemplo, possa compreender questões da infância e da fase adulta, pois, apesar de agir em um momento específico da escolarização, essa etapa faz parte de um conjunto maior: a educação básica.

É importante, ainda, pensar a formação de um professor que compreenda os fundamentos das ciências e revele uma visão ampla dos saberes. Segundo um grupo de professores da Universidade de Brasília UnB, em um documento sobre formação docente, as "licenciaturas estão condenadas à interdisciplinaridade". Para tanto, ao contrário do que se pensa, o profissional deve realizar estudos aprofundados em uma área específica do conhecimento e, paralelamente, contemplar as reflexões sobre o ensino-aprendizagem dos conceitos mais fundamentais dessa área. Em termos da atuação profissional, significa projetar alguém que trabalhe preferencialmente em uma determinada área do conhecimento escolar, a que se dedique mais, mas que, necessariamente, esteja em contato permanente com outros campos do saber.

Além disso, é fundamental investir na formação de um professor que tenha vivenciado uma experiência de trabalho coletivo e não individual, que se tenha formado na perspectiva de ser reflexivo em sua prática, e que, finalmente, se oriente pelas demandas de sua escola e de seus alunos, e não pelas demandas de programas predeterminados e desconectados da realidade escolar. É fundamental criar, nos cursos de licenciatura, uma cultura de responsabilidade colaborativa quanto à qualidade da formação docente.

Para isso, a familiaridade com os processos e os produtos da pesquisa científica torna-se imprescindível na formação docente. A imersão dos futuros educadores em ambientes de produção científica do conhecimento possibilita-Ihes o exame crítico de suas atividades docentes, contribuindo para aumentar sua capacidade de inovação e para fundamentar suas ações. É o mergulho em tal atividade que permite a mudança de olhar do futuro docente em relação aos processos pedagógicos em que se envolve na escola, à maneira de perceber os educandos e suas aprendizagens, ao modo de conceber e desenvolver o seu trabalho em sala de aula. 
Em discussão recente sobre a formação docente ${ }^{4}$, realizada na UFMG, intelectuais brasileiros e estrangeiros, de reconhecida produção acadêmica no campo educacional, expuseram a necessidade de uma articulação efetiva entre pesquisa, formação inicial e formação continuada dos profissionais da educação. Um dos consensos resultantes desse debate foi o reconhecimento de que as universidades e as demais instituições de ensino superior precisam repensar seu atual modelo de formação de professores e buscar, segundo definiu Carlos Jamil Cury, uma nova cultura institucional das licenciaturas.

Essa noção de nova cultura institucional dos cursos de formação de professores deve ser entendida como a capacidade de as universidades, especialmente as públicas, responderem, de maneira qualitativa, aos desafios propostos pela nova conjuntura política e socioeconômica brasileira. De acordo com o professor acima referido, cabe às universidades públicas assumir o desafio e o compromisso social de formar, de maneira diferenciada, profissionais da educação capazes de atuar como agentes de mudança na escola básica, no Brasil.

Concordando com esse ponto de vista, Magda Becker Soares ressaltou que as universidades cumprem sua função pública ao preparar um tipo diferenciado de professor, e não, necessariamente, ao atender às demandas de mercado. Na opinião dessa professora, as universidades, na qualidade de instituições de ensino, pesquisa e extensão, devem formar professores, sem contudo dissociar essas atividades, ou seja, é necessário haver uma articulação - entendida, aqui, como junção, fusão, união - da formação docente com a pesquisa - compreendida como processo de produção do conhecimento. Concretamente, isso significa que as universidades devem assumir a formação do "professor investigador", um profissional dotado de uma postura interrogativa e que se revele um pesquisador de sua própria ação docente.

A formação do "professor investigador", para Magda Becker Soares, deve resultar da vivência do licenciando, durante sua trajetória na universidade, da pesquisa como processo, o que faz com que o futuro professor não só aprenda mas também apreenda o processo de inves- 
tigação e, o mais importante, incorpore a postura de investigador em seu trabalho cotidiano na escola e na sala de aula.

Para que tal formação aconteça efetivamente, a mesma professora ressalta a importância de os professores-pesquisadores das universidades, formadores de educadores, assumirem, também, uma postura investigativa no que diz respeito à sua própria ação docente. Por desempenharem, nessas instituições, o papel de produtores do conhecimento, eles têm condições de ultrapassar a função de simples mediadores entre a ciência, o conhecimento, os produtos da pesquisa e o licenciando.

Assim sendo, as instituições formadoras do professor da escola básica devem estar atualizadas nos resultados da pesquisa em sua área, para poderem trabalhar o conhecimento, em sala de aula, no estado em que ele se encontra e no momento em que ele está sendo ensinado. Devem estar, também, atualizadas nos processos de aprendizagem desse conhecimento específico. Quem forma o professor - tanto a instituição quanto as pessoas - precisa estar diretamente envolvido com a atividade de pesquisa. Os formadores precisam ser, também, pesquisadores, para poderem tratar o conteúdo como um momento no processo de construção do conhecimento, ou seja, trabalhar o conhecimento como objeto de indagação e investigação. Precisam ser, finalmente, investigadores de sua própria ação de formadores, dos processos de aprendizagem que ocorrem durante o processo de formação, investigadores de seu próprio processo de ensino.

A propósito, Fernando Hernández acrescenta que todo programa de formação de educadores deve constituir-se em objeto de pesquisa na instituição formadora. Projetos de investigação sobre a formação docente permitem não só refletir sobre a preparação que está sendo realizada nessas instituições, mas, fundamentalmente, reconstruir a proposta de formação delas. O professor Hernández lembra ainda que a avaliação assume um papel essencial nesse tipo de pesquisa e constitui um componente importante na reconstrução do próprio processo de formação de professores.

O princípio da pesquisa como um imperativo na formação docente propõe questões importantes a respeito da definição do locus de preparação dos profissionais da educação no Brasil. Esse tem sido um tema polêmico nas atuais discussões sobre a formação de professores. 


\section{O locus da formação docente}

A lei $n^{\circ} 9.394 / 96$, conforme estabelecido no art. 62 , autoriza apenas duas instituições para promover a formação dos profissionais da educação básica no Brasil: as universidades e os Institutos Superiores de Educação. A novidade são esses institutos, recém-criados no cenário educacional brasileiro e inspirados em modelos de formação docente de outros países. A essa nova instituição foi destinado todo um artigo da LDB, o art. 63, com três incisos, no qual se estabelece que programas de formação inicial e continuada de profissionais para a educação básica, em todos os níveis, também devem ser mantidos por ela. Além disso, dois pareceres - CP n 53/99 e CP $n^{\circ} 115 / 99$ - foram aprovados pelo Conselho Nacional da Educação (CNE), e sugerem diretrizes gerais para os Institutos Superiores de Educação (ISE).

O último parecer emitido pelos conselheiros do CNE - CP $n^{0} 115 /$ 99 - define os Institutos Superiores de Educação como

(...) centros formadores, disseminadores, sistematizadores e produtores do conhecimento referente ao processo de ensino e de aprendizagem e à educação escolar como um todo, destinados a promover a formação geral do futuro professor da educação básica.

De acordo com a interpretação dos conselheiros dessa instituição do art. 62 da LDB, "as licenciaturas mantidas fora das universidades e centros universitários devem ser incorporadas a institutos superiores de educação". Assim sendo, apesar de não estar vedada às instituições universitárias a organização desses institutos em seu interior, os ISE foram pensados como um locus de formação docente para funcionamento fora das universidades.

Como se sabe, em decorrência da expansão do ensino superior brasileiro sobretudo por via da iniciativa privada, há muito essa formação vem se desenvolvendo em instituições não-universitárias, por meio de cursos de preparação docente de qualidade bastante questionável, que, com raríssimas exceções, se limitam a reproduzir, de maneira empobrecida e piorada, os modelos de formação de professores das universidades. Nessas instituições, conhecidas como "faculdades isoladas", comprova-se 
uma extrema dificuldade em formar profissionais que atuem em todas as áreas do conhecimento escolar, particularmente nas ciências naturais biologia, física e química -, pois, nelas, são os gastos com a manutenção de cursos que determinam as áreas que devem ser privilegiadas.

Sendo assim, novamente perguntar-se-ia: qual é a diferença entre as atuais "faculdades isoladas" e os novos "Institutos Superiores de Educação"? Estão esses "institutos" apenas legitimando as "faculdades isoladas" como um dos espaços destinados à formação docente no país? Ou são os ISE uma versão revista e atualizada dos Centros de Formação e Aperfeiçoamento do Magistério (Cefams)? Os ISE representam a desejada solução para a carência de profissionais habilitados para todas as áreas do conhecimento escolar? Já que não são definidos como instituições de pesquisa, ensino e extensão, de que modo os ISE contemplam o princípio da articulação entre investigação científica, formação inicial e formação continuada dos profissionais da educação? Uma vez que a pesquisa não faz parte de seu cotidiano, como esses institutos vão cumprir aquilo que os define como centros "produtores do conhecimento referente ao processo de ensino e de aprendizagem e à educação escolar como um todo"?

Finalmente, os novos cursos de formação de professores no Brasil deverão ser organizados com base em diretrizes curriculares nacionais, de acordo com o estabelecido na LDB. Apesar de tais referências para os cursos que preparam os profissionais da educação ainda não estarem concluídas, são apresentados alguns comentários sobre o processo de construção dessas diretrizes e algumas tendências que já se observam.

\section{Diretrizes curriculares para os cursos de formação docente}

Antes mesmo de que a LDB fosse sancionada, a lei no 9.131/95, que criou o Conselho Nacional de Educação - CNE, já explicitava, entre as atribuições desse órgão, a deliberação sobre as diretrizes curriculares para os cursos de Graduação (art. 9, parágrafo 2, alínea c). A regulamentação dessa idéia de diretrizes aconteceu, então, com a aprovação da LDB, que estabeleceu como um dos deveres das universidades "fixar os currículos dos seus cursos e programas, observadas as diretrizes gerais pertinentes" (art. 53, inciso II). Além disso, a nova LDB, em seu art. 48, acabou com a vinculação entre certificados de conclusão de curso e exercício profissional, definindo que os diplomas se constituem apenas em prova da forma- 
ção recebida por seus titulares. Conseqüentemente, a figura do currículo mínimo, instrumento legal que determinou a organização dos cursos superiores no Brasil a partir da lei 5.540/71 e conduziu os concluintes desses cursos a diplomas profissionais, foi revogada com a nova lei.

Segundo interpretação dos conselheiros do CNE, expressa no parecer CES nº 776/97, o espírito da nova LDB está voltado para uma maior flexibilidade na organização dos cursos na educação, em geral, e no Ensino Superior em particular. Dessa maneira, os currículos mínimos e sua excessiva rigidez foram considerados extemporâneos, algo que atrapalharia as instituições na busca de inovações e diversificações em suas propostas curriculares. Nos termos desse parecer, "toda a tradição que burocratiza os cursos (...) se revela incongruente com as tendências contemporâneas de considerar a boa formação no nível de graduação como uma etapa inicial da formação continuada".

Em 3 de dezembro de 1997, a Secretaria de Educação Superior do Ministério da Educação - SESu/MEC publicou o edital SESu $\mathrm{n}^{\circ} 4$, convidando as diferentes organizações, entidades e instituições a enviar propostas de diretrizes curriculares para os cursos de graduação superior. Para análise e sistematização dessas propostas, a SESU/MEC compôs uma comissão de especialistas por curso de graduação, com base em indicação de nomes pelas instituições. Todavia não foi criada uma comissão que se responsabilizasse por diretrizes curriculares comuns a todas as licenciaturas. Como conseqüência, as versões finais dos documentos dos cursos que, além do bacharelado, têm a licenciatura contemplaram distintas concepções da formação de professores.

Esses documentos usaram diferentes termos para se referir às licenciaturas - entre outros, curso, modalidade, módulo e habilitação -, o que denota, na verdade, divergências epistemológicas em relação à formação dos profissionais da educação. No caso da matemática, por exemplo, foram construídas duas diretrizes curriculares: uma para a licenciatura, outra para o bacharelado. Já na química, apesar de os especialistas escreverem um único documento, a licenciatura foi explicitamente considerada um curso com características próprias. Por outro lado, a maior parte dos documentos considerou a licenciatura uma modalidade, um módulo ou uma habilitação. Nesse caso, a ênfase recaiu na formação do bacharel. Curiosamente, em alguns desses mesmos documentos previa-se a preparação dos professores em determinada área do conhecimento, porém, sem uma formação básica em educação! 
Quando o processo de construção das diretrizes curriculares já estava bastante avançado na maioria das comissões de especialistas, a SESu/MEC resolveu nomear um "grupo-tarefa", composto por cinco professores ligados à área de educação, com a finalidade de elaborar um documento norteador para as diretrizes curriculares das licenciaturas. Nessa oportunidade, as instituições não foram solicitadas a indicar nomes para esse grupo, nem a enviar propostas para serem analisadas e sistematizadas. Na estratégia montada por essa secretaria, tal documento deveria ser encaminhado a um outro grupo de professores, de áreas específicas, que se encarregaria de coordenar a construção das diretrizes das licenciaturas em cada uma dessas áreas, responsabilizando-se por articular o texto produzido pelo "grupo-tarefa" e as diretrizes das comissões de especialistas.

Espera-se que, apesar de muito tardio e de seguir um trajeto diferente daquele realizado pelas comissões de especialistas, esse processo de construção das diretrizes curriculares dos cursos de formação de professores consiga promover mudanças significativas nas licenciaturas. E que, enfim, essas alterações representem uma superação do atual modelo de preparação dos profissionais da educação e um salto qualitativo para a formação docente no país.

\section{Considerações finais}

Formar professores é uma tarefa bastante complexa. Justamente por isso, não são medidas simplistas e banalizadoras, apresentadas como uma fórmula mais eficiente e produtiva de preparar os profissionais da educação, que irão resolver os problemas atuais das licenciaturas. Ademais, a não-valorização do profissional da educação, os salários aviltantes, as precárias condições de trabalho e a falta de um plano de carreira para a profissão continuam sendo questões fulcrais sem solução, que afetam diretamente a formação docente no Brasil. Os problemas centrais das licenciaturas apenas serão resolvidos, na verdade, com a implantação de mudanças drásticas na atual condição do profissional da educação.

Ao mesmo tempo, fazem-se necessários estudos e pesquisas que respondam a questões essenciais, como "O que é formar professores?" ou "Como formar professores?". Além disso, as universidades e demais instituições de ensino superior precisam continuar trocando informações 
e buscando, em experiências mais significativas, a chave para as questões que dizem respeito aos cursos de formação docente no país.

\section{Notas}

1. Essa continua sendo a orientação política e educacional no Brasil. Para mais informações sobre o tema, sugiro a leitura de De Tomasi, Warde e Haddad (orgs.) 1996.

2. Essa parte do texto retoma algumas considerações realizadas por Mortimer e Pereira 1999.

3. Nessa parte, algumas análises realizadas por Zaidan e Pereira (1998) são recuperadas e ampliadas.

4. Refiro-me ao Fórum das Licenciaturas da UFMG, realizado nos dias 19,20 e 21 de novembro de 1997.

\section{Teaching major and brazilian policies about teacher education}

ABSTRACT: This article presents reflexions and analysis about recent educational policies for Brazilian teacher education. It foccuses on different aspects related to teaching major courses in the country, specially, after the implementation of the new LDBlaw that rules National Educational System -, in 1996.

\section{Bibliografia}

DE TOMASI, Livia; WARDE, Mirian Jorge; HADDAD, Sérgio (orgs.). O Banco Mundial e as políticas educacionais. São Paulo: Cortez, 1996.

MORTIMER, Eduardo Fleury; PEREIRA, Júlio Emílio Diniz. "Uma proposta para as 300 horas de prática de ensino: Repensando as licenciaturas para além do modelo da racionalidade técnica". Educação em Revista nํㅜ 30, nov. 1999.

PEREIRA, Júlio Emílio Diniz. "A formação de professores nas licenciaturas: Velhos problemas, novas questões". Encontro Nacional de Di- 
dática e Prática de Ensino, 9. Anais II, v. 1/2. Águas de Lindóia, 1998, pp. 341-357.

ZAIDAN, Samira; PEREIRA, Júlio Emílio Diniz. "A quem cabe formar o professor da escola básica?". Presença Pedagógica 4 (20), mar./abr. 1998, pp. 89-92. 